

\title{
Gi4DM 2018
}

Geolnformation For Disaster Management

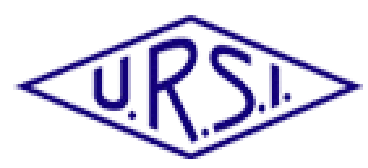

\section{PREFACE}

The increase of natural and anthropogenic disasters is a phenomenon that has been witnessed all around the world. While the scientific knowledge and the technical solutions available to understand and combat this issue are significant, they span a diverse range of disciplines, are sometimes obscure, and often involve great skill to apply in practice. Many of the challenges are interdisciplinary and require sophisticated solutions. These challenges include a wide variety of sensor systems including ground penetrating radars to search for buried people and objects and the opportunistic detection of EM emissions from communications devices including cell phones, PDAs, which can help to locate lost persons. In both cases the radio scientist is involved in the antenna design, the propagation of wideband signals through dispersive ground media and also the signal processing. The remote sensing community then requires sophisticated search and recognition strategies to quickly identify targets.

URSI and ISPRS are two leading global scientific societies providing complementary support and leadership to their respective communities. URSI is responsible for stimulating and co-ordinating, on an international basis, studies, research, applications, scientific exchange, and communication in the fields of radio science. It encompasses the knowledge and study of all aspects of electromagnetic fields and waves. ISPRS is the International Society for Photogrammetry and Remote Sensing. It covers complementary disciplines of interest for a wide scientific community. The Scientific Unions of ISPRS and URSI together possess the knowledge and skills of these domains, and thus, through harmonious and continuous co-operation, offer relevant solutions regarding public protection and disaster relief (PPDR). In 2009, URSI and ISPRS agreed to organize common workshops on "disaster management". Joint sessions where organized in Antalya (2010, GI4DM), Istanbul (2011, URSI GASS), Melbourne (2012, ISPRS GA) with contributions to the "VALID" document (The Value of Geo information for Disaster and Risk Management, 2013), edited by Professor Orhan Altan. As a continuation of the programme, an URSI-ISPRS session was organized during the XXIII ISPRS Congress 2016 in Prague and focused on "Disaster and Risk Management". At the end of the session, the creation of a joint working-group was discussed to support longer-term coordination between ISPRS and URSI.

This intended longer-term coordination between ISPRS and URSI has been reflected in Gi4DM 2018 Geoinformation for Disaster Management conference, held at Istanbul Technical University, Istanbul - Turkey, on 17 - 21st March, 2018. In this conference, it is aimed to address the use of Geolnformation technologies in the disaster management and to create a platform for exchanging the ideas among scholars and practitioners of public and private sectors. The conference addressed diverse topics related to methodologies and technologies within a unique forum keeping participants up to date with the latest advances in disaster management.

The proceedings of the Gi4DM 2018 consist of Archives papers which have been selected based on a review of the submitted abstracts. All Archives abstracts submitted were evaluated by the Scientific Committee according to content, significance, originality, relevance and clearness of presentation. Altogether there have been 67 oral and 19 poster papers included in ISPRS Archive. These, together 
with free pre-conference radar training workshop given to young scientists, serve to demonstrate the importance of the Gi4DM conference for sharing ideas and findings with national and international communities.

We thank to all those who have contributed to producing such a fruitful and successful conference and the members of the Scientific Committee for their valuable reviews. Our special thanks go to four invited speakers Deren Li, Steven Ramage, Ed Parsons and Alik Ismail Zadeh, to the workshop lecturers, to the organizing committee, and to the sponsoring institutions/firms, without whom, this important event would not have been realized. Enough thanks cannot be expressed to Copernicus officers for their successful management of the reviewing process and uploading of papers and final program. Last, but not least we would like to thank Mrs. Ayçıl Yeşilırmak from K2 Conference and Event Management Company, for helping us through everything in successful organization.

\section{Editors:}

Tullio Tanzi (Organizing Committee Chair)

Madhu Chandra (Organizing Committee Co-chair)

Orhan Altan (Local Organizing Committee Chair)

Filiz Sunar (Program Committee Chair)

\section{March, 2018}

